\title{
O GRUPO CORUMBÁ (NEOPROTEROZÓICO-CAMBRIANO) NA REGIÃO CENTRAL DA SERRA DA BODOQUENA (FAIXA PARAGUAI), MATO GROSSO DO SUL
}

\author{
PAULO C. BOGGIANI*,THOMAS R. FAIRCHILD** e ARMANDO M. COIMBRA**
}

\begin{abstract}
THE CORUMBÁ GROUP (NEOPROTEROZOIC-CAMBRIAN) CENTRAL PART OF THE SERRA DA BODOQUENA (PARAGUAI FOLD BELT), MATO GROSSO DO SUL STATE, BRAZIL. The Corumbá Group comprises carbonates and lesser siliciclastics cropping out in a discontinuous belt over $1,400 \mathrm{~km}$ in southwestern Brazil. In the Serra da Bodoquena, southern part of this belt, sedimentation began after latest Proterozoic glaciatipn ( $c a .600 \mathrm{Ma}$ ) in a rift setting that evolved to a carbonate platform with a continental slope to the east (Atlantic-type passive margin) where oceanic upwelling provided phosphorus to the platform margin and turbidites of the Cuiabá Group may have been deposited. Brasiliano tectonism ending around $490 \mathrm{Ma}$ deformed and metamorphosed the eastern internai zone while only mildly modifying the western external zone.
\end{abstract}

Keywords: Deposition model, limestones, phosphate, upwelling.

\begin{abstract}
RESUMO O Grupo Corumbá é composto por carbonatos e rochas silicáticas expostas em faixa descontínua de $1.400 \mathrm{~km}$ de comprimento na região sudoeste do Brasil. Na Serra da Bodoquena, porção meridional da faixa, a sedimentacão teve início após a última glaciação proterozóica $(600 \mathrm{Ma})$, em bacia do tipo rift, que evoluiu para plataforma carbonática com margem continental aberta para leste (margem passiva do tipo Atlântica). Ao longo da margem, teria ocorrido ressurgência marinha que propiciou a formação de rochas fosfáticas na plataforma. Em águas profundas, a leste da margem da plataforma, teriam sido depositados os turbiditos do Grupo Cuiabá. Os sedimentos foram deformados pelo Tectonismo Brasiliano, finalizado ao redor de $490 \mathrm{Ma}$, tendo sido este mais intenso na porção leste, estruturando a zona interna, e incipiente na zona externa, que também engloba a cobertura cratônica.
\end{abstract}

Palavras-chave: Modelo deposicional, carbonatos, fosfato, ressurgência marinha.

INTRODUÇÃO Na Faixa de Dobramentos Paraguai, contornando o Cráton Amazônico, as exposições predominantemente carbonáticas do Grupo Corumbá e correlates se estendem em faixa descontínua de forma curva, convexa para noroeste, do Paraguai (Grupo Itapucumi) ao Brasil (Grupo Corumbá), passando pela Serra da Bodoquena, Corumbá e Serra do Amolar (Mato Grosso do Sul), flexionando-se para NE-E na Serra das Araras, no Estado de Mato Grosso. A partir da Serra do Amolar, ao norte de Corumbá, os calcários do Grupo Murciélago (Bolívia), dispostos em faixa E-W, adentram o Cráton Amazônico.

A IDADE DO GRUPO CORUMBÁ Os indicadores paleontológicos e isotópicos relevantes à datação do Grupo Corumbá convergem para idade no limite Neoproterozóico/ Cambriano. Zaine (1991) considera como evidência de idade vendiana superior a cambriana inferior os invertebrados primitivos Cloudina lucianoi e Corumbella werneri, a alga macroscópica Tyrasotaenia sp. e o microfóssil Sphaerocongregus variabilis (= Bavlinella faveolata) encontrados no topo do grupo apenas em Corumbá. Dados referentes a isótopos de ${ }^{43} \mathrm{C} \mathrm{e}{ }^{87} \mathrm{Sr} /{ }^{86} \mathrm{Sr}$ (Zaine 1991), tanto em Corumbá como na Serra da Bodoguena, embora preliminares, são coerentes com esta ideia. Unica análise radiométrica ( $\mathrm{Rb}-\mathrm{Sr}$, rocha total em siltitos da região de Corumbá) acusou idade de $489 \pm 29$ Ma para eventos termodinâmicos tardios do Ciclo Brasiliano (Cordani et al 1985).

O Grupo Corumbá é posterior à última glaciação proterozóica, evidenciada na Faixa Paraguai pela Formação Puga e equivalentes, e a correlação destes depósitos glaciogênicos com semelhantes na África permite sugerir-lhe a idade máxima em torno de $600 \mathrm{Ma}$ (Alvarenga \& Trompette 1992).

A FAIXA PARAGUAI NA SERRA DA BODOQUENA Sobre a posição na faixa dobrada, marcantes diferenças entre estilos tectônicos e tipos faciológicos permitem distinguir duas zonas paralelas de direção N-S, denominadas por Almeida (1984) de Brasilides metamórficas e Brasilides não-metamórficas, individualizadas no Estado de Mato Grosso (Alvarenga 1988) como zona interna e zona externa, respectivamente.

Na Serra da Bodoquena (Boggiani 1990), a zona externa, com camadas horizontais a pouco deformadas com dobras abertas e flexurais, limita-se a oeste por discordância erosiva com gnaisses e xistos do Complexo Metamórfico Alto Tererê e, a leste, por contatos tectônicos com unidades da zona interna, intensamente deformadas com dobras isoclinais e falhas inversas.

\section{DESCRIÇÃO E INTERPRETAÇÃO DAS FÁCIES}

As fácies sedimentares foram definidas e distribuídas conforme demonstrado na tabela I.

Fácies da zona externa Foram estudadas as fácies que ocorrem na região cortada pelas estradas Bonito - Fazenda Baía das Garças e Três Morros - Vila Gaúcha, onde observa-se todo pacote representativo desta unidade com

\footnotetext{
* Centro de Ciências Exatas e Tecnologia, Universidade Federal do Mato Grosso do Sul, Caixa Postal 649, CEP 79070-900, Campo Grande, MS, Brasil, $\operatorname{Fax}(067)$ 787-3093

** Instituto de Geociências, Universidade de São Paulo, Caixa Postal 11348, CEP 05422-970, São Paulo, SP, Brasil
} 
Tabela 1 - Distribuição das fácies do Grupo Corumbá Table 1 - Facies distribution of the Corumbá Group

Fácies da zona externa
Águas profundas
fácies de mudstones

Ambiente transicional
f. de margas e
mudstones alternados
f. de mudstones
pseudonodulares
Águas rasas
f. de grainstones com
laminações cruzadas
fácies de lamitos
fácies de arcósios

\author{
Fácies da zona interna \\ Águas profundas \\ f. de mudstones calcíticos \\ fácies de lamitos \\ Ambiente transicional \\ f. de brechas com blocos
Águas rasas
f. de brechas com intraclastos placóides
f. de mudstones dolomíticos
f. de grainstones oolíticos

predomínio de terrígenos na

base (arcósios e lamitos), passando no topo para carbonatos (grainstones com laminação cruzada, margas e mudstones pseudonodulares ou com estratificação plano-paralela).

Fácies de arcósios Esta fácies, basal, com 15 a 20 m de espessura, ocorre em discordância erosiva sobre o Complexo Metamórfico Alto Tererê, na borda oeste da Serra da Bodoquena e na região central do Sinclinal do Rio Perdido.

Os arcósios são normalmente maciços, com granulação areia média a grossa, angulosos, matriz síltico-argilosa, e cimento de quartzo microcristalino ou calcedônea fibrorradiada. Os grãos são 70 a $80 \%$ de quartzo e o restante de feldspatos, com predomínio de microclínio. Estruturas sedimentares são raras, restritas às marcas onduladas, estratificação cruzada planar e gradacional. Localmente, ocorrem lentes mais conglomeráticas.

As poucas medidas de estratificações cruzadas sugerem paleocorrentes para leste e derivacão de rochas do Complexo Metamórfico Alto Tererê. A baixa maturidade textural (má seleção e angulosidade dos grãos) e mineralógica (presença de feldspatos) indica ambiente de alta energia e deposição em proximidade da área-fonte, provavelmente ligado a ambiente fluvial entrelaçado.

Fácies de lamitos Na base da seção, os lamitos ocorrem em camadas métricas, intercalados em arcósios e carbonatos, todavia na porção mediana chegam a formar um pacote de 15 a 20 metros de espessura. São maciços ou estratificados, com predomínio de silte e argila e menos de $10 \%$ de areia, e compõem-se de quartzo, muscovita, clorita e feldspato. Correspondem à deposição em ambiente plataformal de baixa energia, distais aos leques aluviais arcosianos, episodicamente alcançados por estes na base da seção, dando lugar à deposição carbonática por ocasião da menor contribuição terrígena.

Fácies de grainstones com laminação cruzada Ocorrem em transição com os arcósios basais (Fazenda Baía das Garças), apresentando laminação cruzada tabular com sets de 10 a $15 \mathrm{~cm}$ de espessura, com mergulhos das lâminas de $15^{\circ}$ a $20^{\circ}$, dispostas, por vezes, como estrutura "espinha de peixe" (Prancha 1, Foto 1).

Os grainstones compõem-se de intraclastos que, ocasionalmente, ocorrem como palhetas irregulares de espessuras submilimétricas e área menor do que $1 \mathrm{~cm}^{2}$, interpretados como fragmentos de laminitos microbianos. Observam-se oóides e esparsos cristais milimétricos de calcita em formato romboédrico, interpretados como pseudomorfos de gipsita.

As estruturas sedimentares presentes indicam ambiente marinho raso, onde a laminação cruzada, predominante- mente unidirecional, mostra acão de correntes com alguma influência de marés (espinha de peixe) e tempestades (hummocks). A transição com arcósios mostra a implantação da plataforma carbonática rasa em momento de calmaria tectônica e aridez climática sem a contribuição terrígena.

Fácies de margas e mudstones alternadas Esta fácies, limitada a um pacote de $5 \mathrm{~m}$ de espessura, em posição estratigráfica mediana, é constituída por estratos de 5 a 15 $\mathrm{cm}$ de margas alternados com mudstones calcíticos (Prancha 1 , Foto 2).

Purser et al. (1987) atribuem a coexistência de terrígenos e carbonatos ao aporte esporádico de terrígenos, resultante de curtos períodos de chuvas torrenciais em ambientes áridos, com rápido retorno da limpidez das águas, fator fundamental para atividade microbiana e consequente produção carbonática.

Fácies de mudstones pseudonodulares Ocorre como pacote de 12 a $15 \mathrm{~m}$ de espessura em transição com a fácies de margas e mudstones alternadas. Os pseudonódulos de mudstones (calcíticos com envoltório de margas laminadas) tabulares com espessuras de 3 a 5 cm (Prancha 1, Foto 3) são produtos de deformação por sobrecarga (boudinage) com adelgaçamento das bordas e fraturas (perpendiculares ao acamamento) com preenchimento por calcita secundária.

Fácies de mudstones Mudstones calcíticos, de cor cinza médio a escura, em camadas plano-paralelas de 10 a $20 \mathrm{~cm}$ de espessura, compõem pacote de, no mínimo, $30 \mathrm{~m}$ de espessura no topo da sucessão da zona externa.

Os mudstones depositaram-se em parte distai da plataforma carbonática, em ambientes de baixa energia sob águas mais profundas, longe da ação de ondas e marés, abaixo da ação de ondas de tempestades.

Modelo deposicional da zona externa Ocorre na zona externa, pacote sedimentar em torno de $180 \mathrm{~m}$ de espessura, que se inicia com sedimentos terrígenos continentais, de ambiente fluvial entrelaçado, onde os desníveis topográficos condicionaram a deposição de fácies de arcósios e lamitos, associadas, provavelmente, a chuvas torrenciais em clima semi-árido, passando, gradativamente, para carbonatos.

Com a transgressão marinha em calmaria tectônica, sem aporte apreciável de terrígenos, houve o predomínio de formação de calcários, com esparsos pseudomorfos de gipsita demonstrando continuidade da aridez climática. A sedimentação dos grainstones, sob influência de marés e de tempestades, teria ocorrido sob condições rasas da plataforma carbonática, em que, lateralmente, os mudstones calcários representariam ambientes mais profundos, dominando para o topo com o máximo da transgressão.

Fácies da zona interna Foram identificadas seis fácies na zona interna. Devido às deformações tectônicas, porém, não foi possível estabelecer relações estratigráficas precisas, ao contrário da situação da zona externa. Contudo, tomando a estrada Bonito-Bodoquena como referência, observou-se, a oeste, determinada distribuição de fácies e, a leste, tipos faciológicos distintos, que, juntamente, possibilitaram a interpretação do modelo deposicional da zona interna. Ao longo e a oeste desta estrada ocorrem a fácies de brechas com intraclastos placóides centimétricos e a fácies de mudstones dolomíticos enquanto, a leste dela, afloram as fácies de lamitos e de mudstones calcíticos. Em afloramentos próximos à estrada, ocorrem as fácies de grainstones oolíticos e de brechas com blocos e as ocorrências de rochas fosfáticas e fosfatitos. 

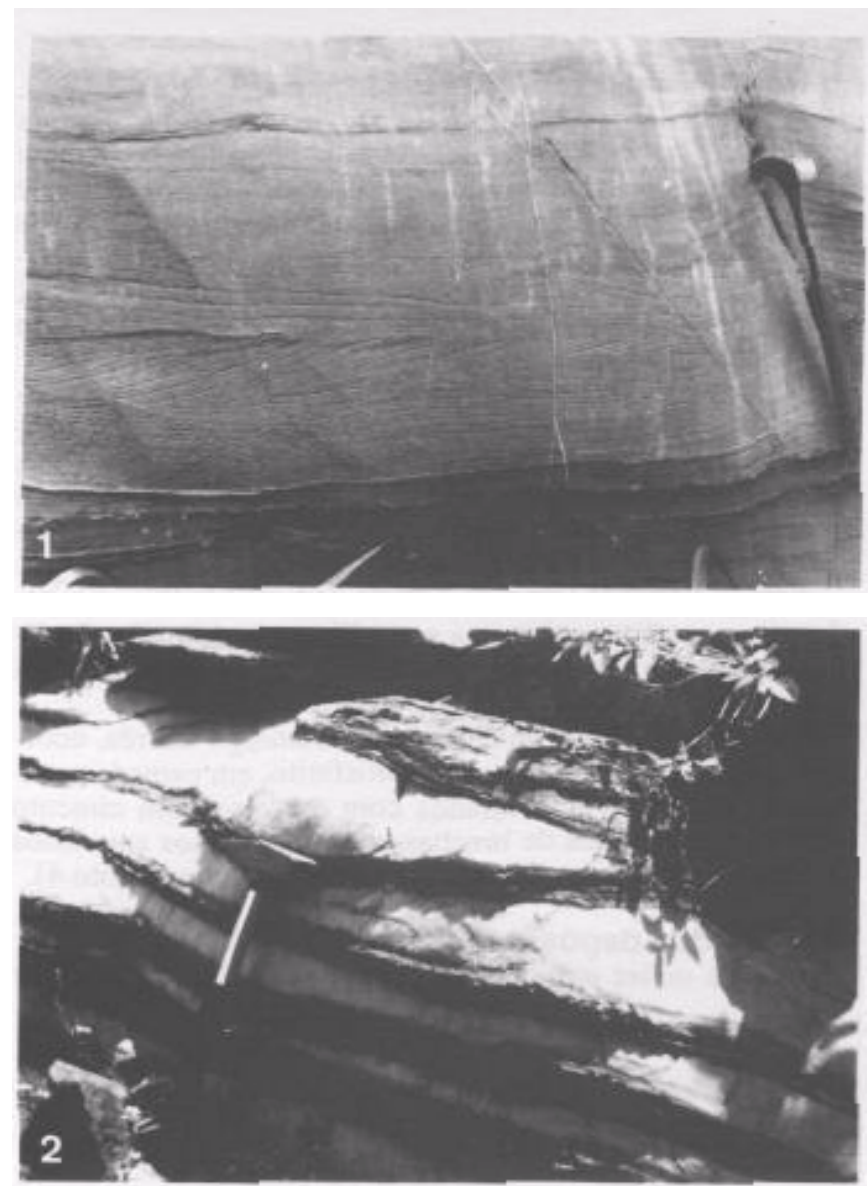
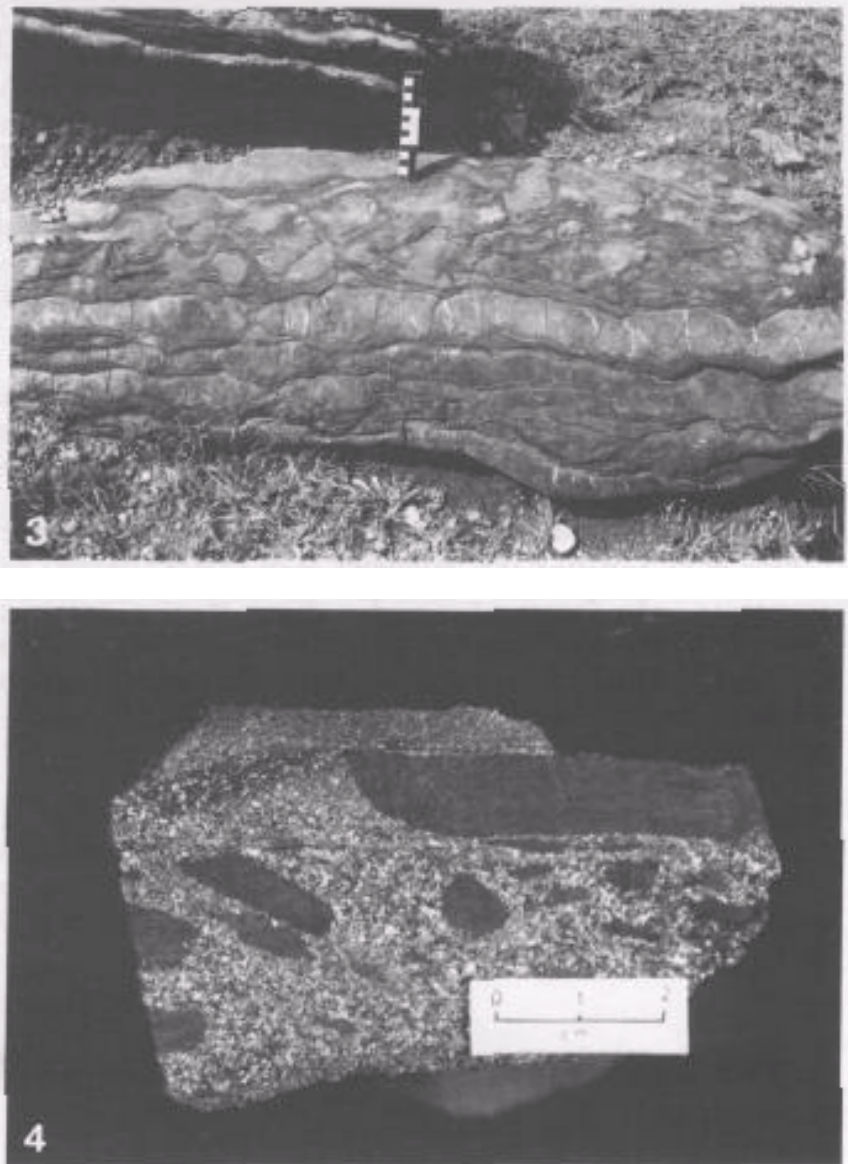

Prancha 1 -Foto 1. Fácies de grainstones com laminação cruzada; Foto 2. Fácies de margas e mudstones alternados; Foto 3. Fácies de mudstones pseudonodulares; Foto 4. Intraclastos de microfosfatito em matriz arcosiana

Plate 1 -Photo 1. Cross-laminated grainstones facies; Photo 2. Alternating marl/mudstones facies; Photo 3. Pseudonodular mudstone facies; Photo 4. Intraclasts of microphosphatite in an arkosic matrix

Fácies de brechas com intraclastos placóides centimétricos A presença de intraclastos placóides centimétricos é comum em pacotes de dezenas de metros de espessura, associados a calcários estratificados, como pode ser observado na morraria da Gruta São Miguel, na fazenda homónima. Os intraclastos encontram-se na forma de placas angulosas, imbricadas ou não, demonstrando pouco ou nenhum retrabaIhamento. Localmente, observam-se níveis contínuos onde as camadas se encontram arqueadas, com concavidade para baixo, constituindo típicas estruturas tepees. Algumas destas placas encontram-se envolvidas por microbialitos e, comumente, entre os intraclastos há grãos arredondados de quartzo. Estas brechas originaram-se da deposição de lamitos carbonáticos sob condições evaporíticas, onde a expansão de cristais de camadas subjacentes às carbonáticas originaram a quebra e arqueamento das placas mais enrijecidas. Por vezes, a disposição das placas sugere origem por dissolução de camadas evaporíticas inferiores.

Fácies de mudstones dolomíticos Nesta fácies, bem representada nos arredores de Bonito, as rochas dolomíticas são homogêneas, no geral maciças, com camadas de um a dois metros de espessura. Apresentam cristalização fina e cores variadas, como branca, avermelhada, alaranjada e cinza, com predomínio desta última.

Localmente, observa-se laminação plano-paralela, ressaltada por lâminas milimétricas de sílica incolor, microcristalina. Fosfato de baixo teor foi detectado disseminado em uma amostra e preenchendo fraturas milimétricas.
Dolomitos recentes são observados em regiões evaporíticas, como nas lagoas Coorong, Austrália (Botz \& Von Der Borch 1984), em sabkhas do Kuwait e também em regiões de clima tropical úmido como nas Bahamas.

A presença de clima árido constatado durante a sedimentação na zona externa torna possível a origem dos dolomitos em ambientes rasos associados a sabkhas litorâneas.

Fácies de grainstones oolíticos Nesta fácies, os oóides ocorrem em lentes de um metro de espessura por quatro a cinco metros de comprimento entre grainstones, observadas ao longo da estrada Bonito-Bodoquena Os oóides são elipsoidais e bem selecionados, geralmente caracterizados por uma lâmina envoltória e o interior recristalizado.

Esta fácies representa ambiente de água agitada e rasa em plataforma carbonática.

Fácies de brechas com blocos A fácies de brechas intraformacionais com clastos de formas e litologias variadas ocorre como uma camada única com espessura de 15 a $20 \mathrm{~m}$ em faixa de direção N-S, por 20 a $30 \mathrm{~km}$ desde a Fazenda Campo Alegre até a Fazenda Bocaiuva, ao longo da rodovia Bonito-Bodoquena. A rocha é sustentada pela matriz (lama dolomítica maciça), com 10 a $30 \%$ de intraclastos, constituídos por mudstones, grainstones oolíticos, sílex e microfosfatito (com até $35 \%$ de $\mathrm{P}_{2} \mathrm{O}_{5}$ ). Na Fazenda Colina, foi observado clasto de estromatólito colunar silicificado. 
A natureza diferenciada dos intraclastos, gerados em distintos ambientes deposicionais (porém todos de águas rasas) permitem interpretar a rocha portadora destes como brecha de talude. A distribuição desta fácies em faixa norte-sul sugere que deveria ser esta a orientação da antiga borda da plataforma. $\mathrm{O}$ material originado na plataforma rasa, a oeste, como os estromatólitos e fosfatitos, por exemplo, teria sido depositado como blocos talude abaixo, por fluxos gravitacionais.

Fácies de lamitos e fácies de mudstones calcíticos Tanto os lamitos como os mudstones caleíticos formam pacotes homogêneos com espessuras de dezenas de metros em dobras isoclinais a leste da cidade de Bonito.

Estas fácies foram mapeadas como Grupo Cuiabá por Corrêa et al (1976) e por Nogueira et al f 1978) devido ao padrão estrutural e à concentração de veios de quartzo; entretanto, não foram observadas discordâncias erosivas com as fácies anteriormente descritas, sendo seu contato tectônico, o que permite considerá-las como parte do Grupo Corumbá, representando fácies de água profunda em contraposição às fácies de água rasa situadas a oeste.

Rochas fosfáticas $\mathrm{Na}$ região de Bonito, Luz et al (1980) individualizaram seis corpos de lamitos contendo níveis fosfáticos, totalizando reserva inferida de quatro milhões de toneladas com teor médio em torno de $6 \%$ de $\mathrm{P}_{2} \mathrm{O}_{5}$.
Novas ocorrências foram descobertas (Boggiani 1990, Boggiani et al. 1992) em associação sedimentar distinta das descritas por Luz et al (1980), permitindo delinear faixa mineralizada, descontínua, de cinco quilômetros de largura e dezenas de quilômetros de comprimento, situada a norte-noroeste de Bonito, ao longo da rodovia BonitoBodoquena, nas fazendas Colina, Bocaiuva e Ressaca, bem como na área da fábrica de cimento da Camargo Corrêa em Bodoquena.

$\mathrm{Na}$ fazenda Colina, intercalados a lamitos, estão presentes camadas fosfáticas com seixos e calhaus de microfosforito e lentes métricas de arenito com cimento fosfático. Nas fazendas Bocaiuva e Guajuvira comumente se observa clastos e grãos arredondados centimétricos de microfosforito maciço na fácies de brecha com blocos.

Está na Fazenda Ressaca, a norte da Fazenda Pitangueira, a melhor ocorrência de rochas fosfáticas, onde são encontrados estromatólitos colunares e oncólitos em dolomito fosfático associado a microfosfatito poroso, preto e branco, com estratificação incipiente, localmente estromatolítico.

$\mathrm{Na}$ área da fábrica de cimento da Camargo Corrêa, ocorrem dolomitos fosfáticos e microfosfatito, em camadas centimétricas pretas, intercalados com arcósios com cimento fosfático e camadas de brechas com intraclastos angulosos de microfosfatito em matriz arcosiana (Prancha 1, Foto 4).

Gênese dos depósitos de fosfato sedimentar A origem da maior parte dos depósitos de fosfato sedimentar

\section{0) Sedimentagdo do Grupo Corumba}

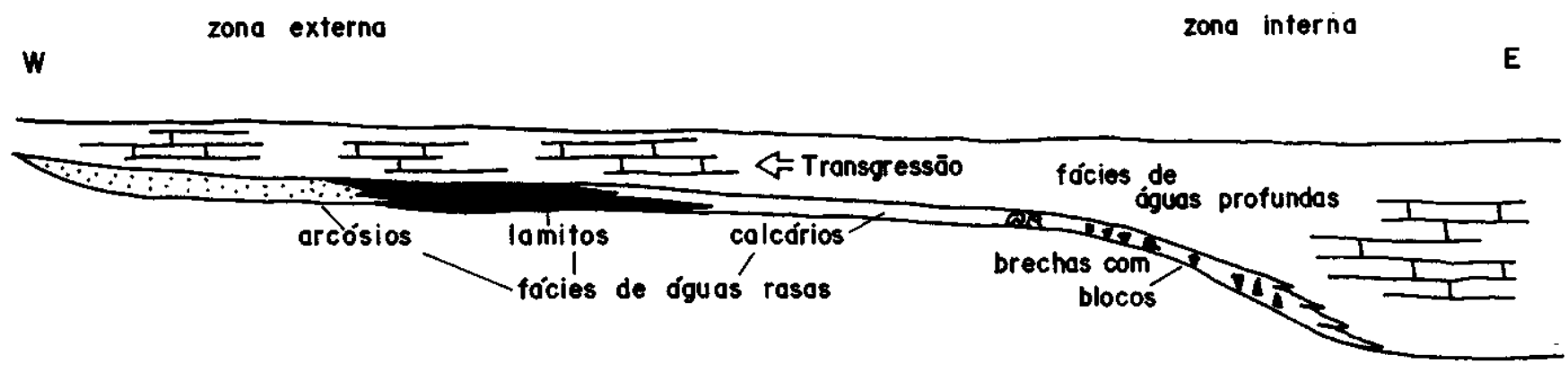

1b) Deformagazo Brasiliana - Estruturagao da Faixa Paragual

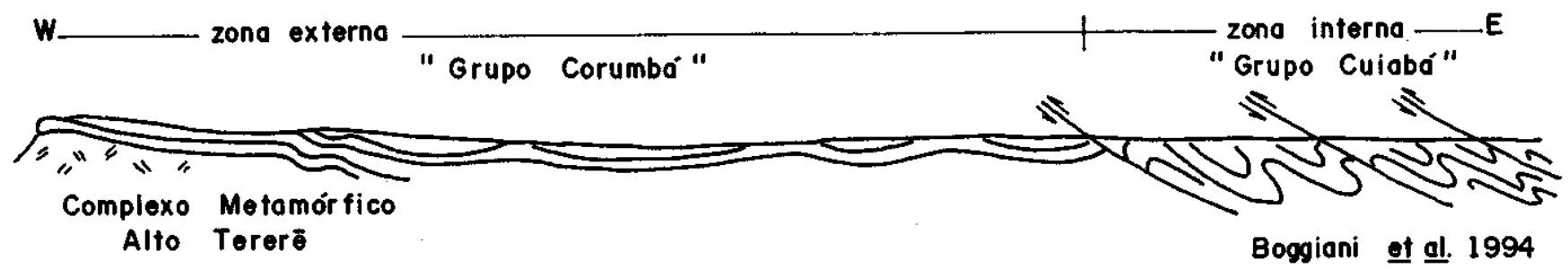

Figura 1 - Modelo paleogeográfico para o Grupo Corumbá na Serra da Bodoquena (MS)

Figure 1 - Paleogeograhic model of the Corumbá Group in the Serra da Bodoquena 
tem sido interpretada como associada a correntes marinhas ascendentes (ressurgência), com base em modelo proposto por Kazakov (1937) devido a presença de nódulos fosfáticos em áreas de ressurgência marinha atual, como ao longo das costas peruanas e chilenas (Burnett 1977) e da Namíbia (Slansky 1980).

Zonas de ressurgência ocorrem em regiões litorâneas sob condições bem definidas relacionadas ao movimento de correntes marinhas, calor solar, regime de circulação atmosférica e força de-Coriolis. Estas regiões são caracterizadas pela ascenção de águas frias ricas em nutrientes dissolvidos, provindos de regiões oceânicas profundas, onde o teor de fosfato chega a até cinco vezes ao valor do teor das águas superficiais. Conseqüentemente, estas áreas apresentam intensa proliferação de vida, especialmente fitoplâncton, e com a acumulação de restos destes pode-se concentrar altos teores de fosfato. São necessárias, porém, decomposição e modificações pós-deposicionais para a formação de fosforitos. Lucas \& Prévôt $(1981,1984)$ produziram apatita, em laboratório, sob condições próximas às encontradas na natureza, utilizando matéria orgânica como fonte de fósforo. Em estudos subsequentes, usaram fragmentos de carbonato sólido como fonte de cálcio (Lucas \& Prévôt 1985), o que resultou na formação de apatita por substituição do carbonato por meio da atividade microbiana.

Com base nestas considerações, os depósitos de rocha fosfática do Grupo Corumbá são interpretados como originados em áreas de ressurgência na borda da plataforma carbonática da zona interna, hipótese esta apoiada pela posição das ocorrências no limite entre fácies sedimentares de águas rasas e profundas. A associação dos fosfatitos e rochas fosfáticas com estromatólitos reforça esta ideia, pois nestas áreas devem ter havido intensa atividade biológica. Desta manei$\mathrm{ra}$, os fosfatitos e rochas fosfáticas foram originados em água rasa na plataforma, posteriormente ressedimentados no talude.

Modelo deposicional da zona interna Com referência à estrada Bonito-Bodoquena (MS), concentramse, a oeste, fácies de águas rasas (grainstones, brechas intraclásticas com clastos placóides centimétricos e dolomitos) e, a leste, fácies de águas mais profundas (lamitos e mudstones calcíticos). Em posição transicional ocorrem fácies de brechas com blocos e rochas fosfáticas. Durante calmaria tectônica e, portanto, com inibição do aporte de terrígenos, o contraste entre águas rasas e profundas teria sido propício para o fenômeno de ressurgência marinha, responsável pelo fornecimento de fósforo na margem da plataforma.

\section{PROPOSTA DE MODELO PALEOGEOGRÁFICO PA- RA O GRUPO CORUMBÁ NA SERRA DA BODO-} QUENA Na região central da Serra da Bodoquena (Fig. 1a), a sedimentação do Grupo Corumbá é caracterizada na base por terrígenos continentais a plataformais rasos (arcósios e lamitos). Com a aridez climática, estes são sucedidos na zona interna pela instalação de plataforma carbonática com borda demarcada por recifes estromatolíticos. No talude, redepositaram-se intraclastos da plataforma, inclusive rochas fosfáticas. As rochas fosfáticas, relacionadas às ressurgências, teriam o suprimento de fósforo de ambientes francamente oceânicos.

Com o máximo da transgressão, os pacotes de dezenas de metros de calcário calcítico (fácies de mudstones calciücos), associados com terrígenos finos (fácies de margas e mudstones alternados e fácies de mudstones pseudonodulares), depositaram-se em águas profundas avançando sobre a zona externa.

Com a deformação brasiliana, ocorreu a estruturação da Faixa Paraguai conforme esquematizado na figura $\mathrm{lb}$.

Agradecimentos Os autores agradecem a Fundação de Amparo à Pesquisa do Estado de São Paulo (FAPESP, Processos 85/2933-2 e 86/0187-4) e a Secretaria de Estado de Turismo, Indústria e Comércio de Mato Grosso do Sul (especialmente, a antiga Companhia de Desenvolvimento da Indústria, Comércio e Mineração de Mato Grosso do Sul, CODESUL), pelo auxilio financeiro e apoio logístico para este projeto.

\section{REFERÊNCIAS BIBLIOGRÁFICAS}

ALMEIDA FFM 1984 Província Tocantins, setor sudoeste. In: ALMEIDA, F.F.M. \& HASUI, Y. coords. O Pré-Cambriano do Brasil. São Paulo, Ed. Blücher Ltda. p. 265-281.

ALVARENGA, C.J.S. 1988. Turbiditos e a glaciação do final do Proterozóico Superior no cinturão dobrado Paraguai, Mato Grosso. Rev. Bras. Geoc. 18(3):323-327.

ALVARENGA, C.J.S. \& TROMPETTE, R. 1992. Glacially influenced sedimentation in the later Proterozoic of the Paraguay belt (Mato Grosso, Brazil). Palaeogeogr. Palaeoclimatol. Palaeoecol, 92:85-105.

BOGGIANI, P.C. 1990. Ambientes de Sedimentação do Grupo Corumbá na Região Central da Serra da Bodoquena, Mato Grosso do Sul. São Paulo. 91 p. (Dissertação de Mestrado. IG-USP).

BOGGIANI, P.C.; COIMBRA, A.C.; FAIRCHILD, T.R. 1992. Calcários e rochas fosfáticas do Grupo Corumbá na Serra da Bodoquena: modelo genético. In: JORNADAS CIENTIFICAS, 2. São Paulo, 1992. Bol IG-USP, Publ. Esp., 12:23-24.

BOTZ, R.W. \& VON DER BORCH, C.C. 1984. Stable isotope study of carbonate sediments from the Coorong área, South Austrália. Sedimentology, 31:832-834.

BURNETT, W.C. 1977. Geochemistry and origin of phosphorite deposits of Peru and Chile. Geol. Soc. Am. Bull, 88:813-823

CORDANI, U.G.; THOMAZ-FILHO, A.; BRITO-NEVES, B.B.; KAWASHITA, K. 1985. On the applicability of the Rb-Sr method to argillaceous sedimentary rocks: some examples from Precambrian sequences of Brazil. Giornale di Geologia, Ser. 3, 47(1-2):253-280.

CORREA, J.A.; CORREIA-FILHO, F.C.L.; SCISLEWSKI, G.; NETO, C.; CAVALLON, L.A.; CERQUEIRA, N.L.S.; NOGUEIRA, V.L. 1976. Geologia das Regiões Centro e oeste de Mato Grosso do Sul. Projeto Bodoquena. (Mapa Geol. Escala 1:250 000). Brasília, DNPM. 111 p. (Série Geologia Básica 3).

KAZAKOV, A.V. 1937. The phosphate facies: origin of the phosphorite and the geologic factors of formation of the deposits. Proc. Sci. Inst. Fertilizers and Insectofungicides, 145:1-106.
LUCAS, J. \& PRÉVÔT, L. 1981. Synthèse d'apatite à partir de matière organique phosphorée (ARN) et de calcite par voie bactérienne. C.R Acad. Sci., Sér. 2. 292:1203-1208.

LUCAS, J. \& PRÉVÔT, T. 1984. Synthèse d'apatite par voie bactérienne à partir de matière organique phosphatée et de divers carbonates de calcium dans les eaux douce et marine naturelles. Chem. Geol, 42:101-118.

LUCAS, J. \& PRÉVÔT, L. 1985. The synthesis of apatite by bacterial activity mechanism. Sci. Geol, Mem., 77:83-92.

LUZ, J. S.; MARQUES, V.J; ABREU-FILHO, W ; BRANDÃO, I.A. MELLO, J.C.R. 1980. Projeto Fosfato de Bonito. Goiânia, Convénio CODESUL/CPRM. 41 p. (Relatório de Prospecção Preliminar).

NOGUEIRA, V.L.; OLIVEIRA, C.C.; FIGUEIREDO, J.A.; CORREA-FILHO, F.C.L: SCISLEWSKI, G.; SOUZA, M.R; MORAES-FILHO, J.C.R.; LEITE, E.A.; SOUZA, N.B.; SOUZA, J.O; CERQUEIRA, N.L.S.; VANDERLEI, A.A.; TAKASCHI, A.T.; ABREU-FILHO, W; ROSITO, J.; OLIVATTI, O.; HAUSEN, J.E.P.: GONÇALVES, G.N.D.; RAMALHO, R.; PEREIRA, L.C.B. 1978. Projeto Bonito Aquidauana. Goiânia, DNPM/CPRM. 14 v. (Relatório Final, arquivo técnico da Divisão de Geologia e Mineração 2744).

PURSER, B.H.; SOLIMAN, M.; M'RABET, A. 1987. Carbonate, evaporite, siliciclastic transitions in Quaternary rift sediments of the northwestern Red Sea. Sediment. Geol, 53:247-267.

SLANSKY, M. 1980. Géologie des phosphates sédimentaires. Mémoire du BRGM, 144:1- 95 .

ZAINE, M.F. 1991. Análise dos Fósseis de Pane da Faixa Paraguai (MS, MT) e Seu Contexto Temporal e Paleoambieníal. São Paulo. 218 p. (Tese de Doutoramento, IG-USP). 